\title{
Ultrasound
}

\section{ASSESSMENT OF LUTEAL FUNCTION IN TOGGENBURG GOATS BY COMPUTER-ASSISTED} IMAGE ANALYSIS

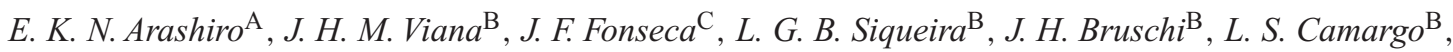
C. A. C. Fernandes ${ }^{\mathrm{D}}$, and F. Z. Brandao ${ }^{\mathrm{A}}$

${ }^{A}$ Federal Fluminense University, Niteroi, Rio de Janeiro, Brazil;

${ }^{\mathrm{B}}$ Embrapa Dairy Cattle, Juiz de Fora, Minas Gerais, Brazil;

${ }^{\mathrm{C}}$ Embrapa Goats, Sobral, Ceara, Brazil;

Diotran, Alfenas, Minas Gerais, Brazil

Computer-assisted image analysis is a technological extension of reproductive ultrasonography and allows the quantitative assessment of the luteal echotexture, which is related to changes in histological features and, consequently, to steroidogenesis. The aim of this study was to determine the 
efficiency of luteal echotexture evaluation as a tool to assess luteal function in different phases of the estrous cycle in Toggenburg goats. Nulliparous goats $(n=21), 8$ months in age, $33.52 \pm 1.22 \mathrm{~kg}$ of body weight, and body score condition of $3.5 \pm 0.07$ ( 1 to 5 scale), which showed estrus within a 48-h period during the natural breeding season (March and April), were used. After estrous detection (Day 0) and mating, ovarian sonographic evaluations were performed daily using a portable ultrasound device (Aloka SSD 500, Aloka Co.) equipped with an adapted linear transrectal 5-MHz probe. The examinations were preceded by blood sample collections, which were stored until radioimmunoassay for progesterone (P4). Images were recorded in VHS tapes, then digitized to TIFF files (resolution of $1500 \times 1125$ pixels) using a video capture board. A representative elementary area of 5625 pixels $\left(0.31 \mathrm{~cm}^{2}\right)$ was defined for the luteal tissue according to the criterion proposed by Van den Bygaart and Protz 1999. Computer-assisted analyses were performed using custom-developed software (Quantporo ${ }^{\circledR}$ ). Each pixel received a numeric value ranging from 0 (black) to 255 (white). Luteal echotexture and plasma P4 data were analyzed by ANOVA, and differences among means were determined by Tukey's test. Correlations were established by Pearson's correlation method. Results are shown as mean \pm SEM. Corpora lutea size increased progressively $(P<0.001)$ until Day 9, when it reached the maximum area $\left(1.26 \pm 0.32 \mathrm{~cm}^{2}\right)$. No increase in size was detected on the subsequent days $(P>0.05)$. Plasma P4 levels increased until a maximum value on Day $9\left(6.31 \pm 0.46 \mathrm{ng} \mathrm{mL}^{-1}\right)$, and no increase was observed further $(P>0.05)$. In nonpregnant animals $(n=7)$, luteolysis was characterized by an abrupt decrease in plasma P4 concentration, which dropped to values lower than $1 \mathrm{ng} \mathrm{mL} \mathrm{mL}^{-1} 24 \mathrm{~h}$ after the onset of the process, whereas luteal area decreased gradually. Plasma P4 concentration was correlated to luteal area during luteogenesis and luteolysis $(\mathrm{r}=0.63$ and $\mathrm{r}=0.50$, respectively; $P<0.05)$. Mean pixel value showed a progressive increase during luteogenesis and reached the maximum value on Day $13(54.33 \pm 1.83)$. During corpus luteum (CL) regression, mean pixel value decreased to lower values $48 \mathrm{~h}$ after the onset of natural luteolysis $(P<0.05)$. Through both luteogenesis and luteolysis, positive correlations were observed between mean pixel values and luteal area $(\mathrm{r}=0.34$ and $\mathrm{r}=0.26$, respectively; $P<0.05)$ and also between mean pixel values and plasma $\mathrm{P} 4$ concentration $(\mathrm{r}=0.24$ and $\mathrm{r}=0.37$, respectively; $P<0.05)$. Pixel heterogeneity was not correlated to luteal area nor plasma P4 levels. These results suggest an association between CL echotexture and steroidogenic function; therefore, the quantitative assessment of the pixel brightness has a potential to be used for luteal function evaluation in goats.

\title{
FAPEMIG and CAPES
}

\section{EARLY PREGNANCY DIAGNOSIS USING A NOVEL TRANSRECTAL ULTRASONOGRAPHY PROTOCOL IN JAPANESE BLACK COWS}

\author{
A. Gaja ${ }^{\mathrm{B}}$, C. Kubota ${ }^{\mathrm{A}}$, and T. Kojima ${ }^{\mathrm{A}}$ \\ ${ }^{\text {A }}$ Kagoshima University, Kagoshima, Japan; \\ ${ }^{B}$ Yamaguchi University, Yamaguchi, Japan
}

The present study aims to establish a novel practical protocol for early pregnancy diagnosis in cows by using transrectal ultrasonography. The protocol is based on measurements of corpus luteum (CL) cross-sectional area (CL c-s area) change performed at 2 separate days before the coming estrus after AI. Fourteen cows were inseminated artificially, and transrectal ultrasonographical observation of the ovaries and blood collection for measurement of peripheral plasma progesterone ( $\mathrm{P} 4$ ) concentration were carried out daily from Days 12 to 23 (Day $0=$ the day of onset of estrus). Thereafter, cows were routinely diagnosed for pregnancy at Day 30 by transrectal ultrasonography. The largest CL c-s area was obtained at Day 14 in both pregnant and non-pregnant cows. Seven out of 8 non-pregnant cows showed significant CL c-s area regression between Days 14 and 20 $\left(422 \pm 112\right.$ v. $\left.249 \pm 63 \mathrm{~mm}^{2}\right)$, whereas no regression was observed between Days 14 and 20 in pregnant cows $\left(416 \pm 65 v .402 \pm 78 \mathrm{~mm}^{2}\right)$. The regression in the CL c-s area between pregnant and non-pregnant cows was significantly different during Day $18\left(424 \pm 65 v .288 \pm 88 \mathrm{~mm}^{2}\right)$ to Day $23\left(402 \pm 71\right.$ v. $\left.139 \pm 64 \mathrm{~mm}^{2}\right)$. P4 concentration was significantly low (less than $\left.1 \mathrm{ng} \mathrm{mL}{ }^{-1}\right)$ at Day 20 in 3 out of 8 non-pregnant cows, whereas the pregnant cows showed significant increase of P4 between Days 14 and $20\left(2.6 \pm 0.2 v .3 .4 \pm 0.5 \mathrm{ng} \mathrm{mL}^{-1}\right)$. The pregnant cows showed significantly higher P4 concentration starting from Day 18 than non-pregnant cows. However, in non-pregnant cows, 4 cows returned to estrus on Day 20 or after, 3 cows showed no signs of estrus, and 1 cow came in estrus as early as Day 18 after AI. In conclusion, the results of the present study suggest that measuring the change in the CL c-s area at Days 14 and 20 makes it possible to detect the non-pregnant cows at Day 20 after AI. However, it was also indicated that measuring the change of P4 concentrations on the same days did not always successfully detect non-pregnant cows. The new protocol based on CL c-s area regression rate can detect almost certainly non-pregnant cows at Day 20 after AI. It is suggested that this method is advantageous in research and industrial breeding.

\section{USE OF PERIFOLLICULAR BLOOD FLOW TO PREDICT THE DEVELOPMENTAL COMPETENCE OF BOVINE CUMULUS-OOCYTE COMPLEXES COLLECTED DURING REPEATED OVUM PICKUP SESSIONS ONCE OR TWICE WEEKLY}

\author{
A. Hanstedt ${ }^{\mathrm{A}}$, K. Höffmann ${ }^{\mathrm{A}}, \ddot{A}$. Honnens ${ }^{\mathrm{A}}$, H. Bollwein ${ }^{\mathrm{A}}$, and C. Wrenzycki ${ }^{\mathrm{A}, \mathrm{B}}$ \\ ${ }^{A}$ University of Veterinary Medicine Hannover, Clinic for Cattle, Hannover, Germany; \\ ${ }^{B}$ University of Veterinary Medicine Hannover, Reproductive Medicine Unit, Hannover, Germany
}

On average, only $20 \%$ of the cumulus-oocyte complexes (COC) develop to the blastocyst stage (Merton et al. 2003 Theriogenology 59, 651-674). An increase in the blood supply to individual follicles appears to be associated with follicular growth rates, whereas a reduction seems to be closely related to follicular atresia (Acosta et al. 2003 Reproduction 125, 759-767). The purpose of this study was to determine whether qualitative perifollicular blood flow changes can be used to predict the developmental competence of COC collected during repeated ovum pickup (OPU) sessions once or twice weekly. Lactating Holstein cows $(n=20)$ were used as oocyte donors. After dominant follicle removal, OPU was performed twice (group 1, for 3 weeks) or once (group 2, for six weeks) weekly employing a 7.5-MHz transducer (GE 8C-RS) of an ultrasound scanner (GE Logiq Book). 